\title{
The Social Limits of Reconstructive Surgery: Stigma in Facially Disfigured Cancer Patients
}

\author{
Alessandro Bonanno \\ Texas State University System Regents Professor of Sociology \\ Department of Sociology, Sam Houston State University
}

USA

\section{Introduction}

The last few decades have been particularly significant in terms of advancements of scientific knowledge and medical knowledge in particular. Within medicine, reconstructive surgical procedures have achieved spectacular results. While the popularity of elective cosmetic procedures has reached unprecedented - and in some instances socially concerning - proportions, the beneficial effects of reconstructive surgery for trauma and/or disease generated cases have been significant. This is also the instance of patients affected by cancer of the head and neck. The multiplicity and frequencies of these forms of cancers now generate a large enough group of patients who face the condition of survivors with an added social problem: The stigma of being facially disfigured.

This chapter probes the issue of the limits of reconstructive surgery as a form of intervention that while addresses relevant medical problems, it also opens up new social problems. In this case, the issue studied is the social consequences of reconstructive surgery on head and neck cancer patients. In particular, this chapter investigates the manner in which social stigma is generated as cancer survivors re-enter society after reconstructive surgery and associated treatments concluded their cancer therapies.

Developments recorded in medicine increasingly generate the long term survival of cancer patients (American Cancer Society, 2009; Mood 1997; Davis, Wingo and Parker 1998). These medical improvements have also had beneficial results for head and neck patients (Davis, Roumanas and Nishimura 1997; Dropkin 1999). In the instance of this particular group of patients, needed surgical intervention signifies the removal of portions of the face that are affected by the malignancy. One of the common consequences of this type of intervention is the alteration of the patient's face and the permanent facial disfigurement that it entails (American Cancer Society, 2009). Surgical procedures to restore the original facial appearance are common. Similarly common is the availability of increasingly sophisticated albeit often costly and difficult to use - prostheses (Davis, Roumanas and Nishimura 1997). Reconstructive surgery is central in the processes and its success is evident. However, the severity of the alterations caused by the removal of the malignancy, make a restoration of the normal shape of the face virtually impossible. The result is that the survival of the 
patient and the success of the surgical interventions and medical treatments translate into a social problem: patients remain facially disfigured. Survivors typically live the rest of their lives with facial disfigurement.

Because of the importance of the face in social relations -a central element of communication (Kish and Lansdown, 2000; Macgregor, 1990), and an item employed to attribute both "normality" and ownership of socially desirable characteristics (Furness, Garrud, Faulder, Swift 2006; Goffman, 1963; Hawkesworth, 2001; Hughes, 1998; Ishii, Carey, Byrne, Zee and Ishii. 2009; Macgregor, 1974) -individuals with the abnormal face experience stigma and are treated differently than the rest of the members of society. They are labeled as different and treated as such (Bull and Stevens 1981; Callahan 2004:75; Furness et al. 2006; Hawkesworth 2001; Hughes 1998; Kent 2000; Macgregor 1951; 1974; 1990; Millstone 2008). According to available literature, facially disfigured patients' interaction with acquaintances and strangers - these are members of secondary social groups - is viewed as a constant source of stigma. Acquaintances and strangers are seen as exercising prejudice (negative feelings and/or beliefs) and/or discrimination (actual differential treatment) against patients. However, the characteristics of the interaction process have not been clearly mapped out leaving a gap in the available knowledge on the manner in which stigma is actually created (Hughes, 1998; Macgregor 1990; van Doorne, van Waas and Bergsma 1994). The knowledge obtained from this study contributes to the reduction of this gap and can be employed to inform caregivers as they deal with disfigured patients and their families.

\section{Methods}

This is a qualitative research based on in-depth interviews with a purposive sample fifteen cancer patients who underwent surgery to treat head and neck malignancies that affected their facial appearance. Patients were selected through the review of records at a major cancer center located in the Southwest of the United States of America. Eligibility criteria excluded persons under the age of 18 , those who had surgery six month prior to the interview, those who were receiving active cancer therapy at the time of the interview, and those who could not express themselves in English. In-depth individual interviews were conducted between January 2008 and February 2010. Twenty potential participants were contacted. Two of them could not participate for scheduling problems and three refused to be part of the project. Finally, a total of eight men and seven women were interviewed. The median age of these patients was 66 years and the youngest patient was 31 and the oldest 81 . The patients included in the study all underwent orbital exenteration. At the time of the interview, the post-surgical period ranged from ten months to thirty five years and the median was five years. Some patients underwent additional reconstructive and plastic surgical procedures. While the extent of disfigurement varied, all of the patients were left with significant alterations in their facial appearance. An illustration of the degree of disfigurement can be seen through the photos accompanying this chapter. Photos 1 and 2 are illustration of severe cases of disfigurement after ablative surgery. Photo 3 illustrates a case in which surgery allowed the use of a prosthesis that adequately concealed the disfigurement (Photo 4). One family member for each of the participating patients was also interviewed. 


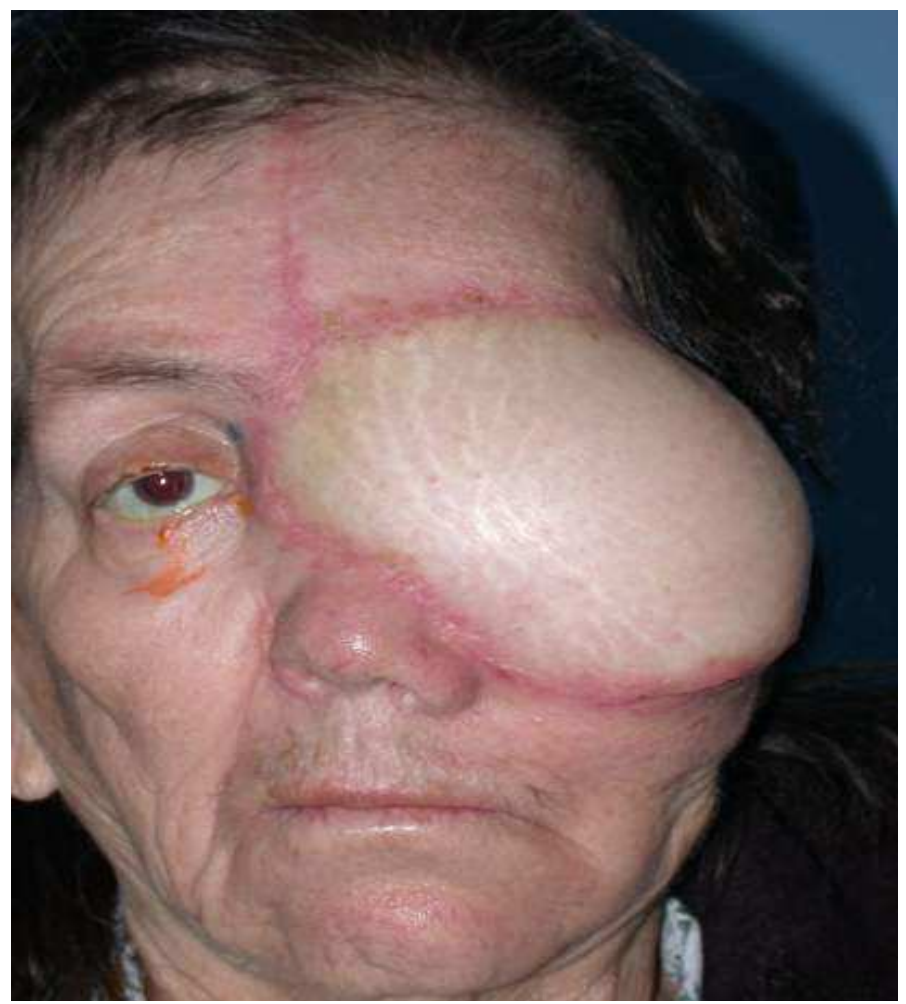

\section{Photo 1}

In the course of the interviews both patients and family members were asked to reconstruct instances of encounters with strangers and acquaintances. The interviews were audio recorded with the participants' and family members' consent and the transcribed texts were analyzed employing the qualitative methodology Grounded Theory (Charmaz 2006). The guiding assumption of the study was to develop analytical categories (variables) that would identify patterns of interaction between facially disfigured cancer patients and members of secondary groups. These categories were created to illustrate the collective action process leading to stigma rather than the manner in which patients felt in the interaction process itself. Analytical categories were constructed through line-by-line coding and constant comparative analysis (Charmaz 2006). Once developed, codes were grouped in relevant categories that were saturated as no new relevant properties of these categories emerged. Along with saturation, the negative cases technique was employed to validate categories and their properties (Charmaz 2006; Holton 2007). In this case, there was a deliberate search for situations that would contradict the analysis. Their absence was employed to validate the conclusions (Charmaz 2006). 


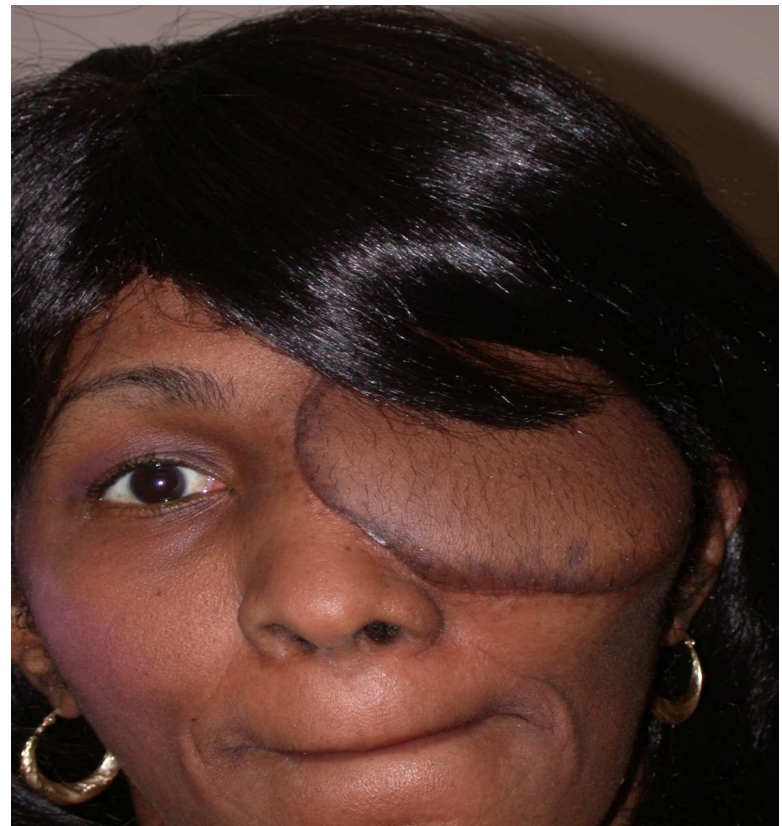

Photo 2

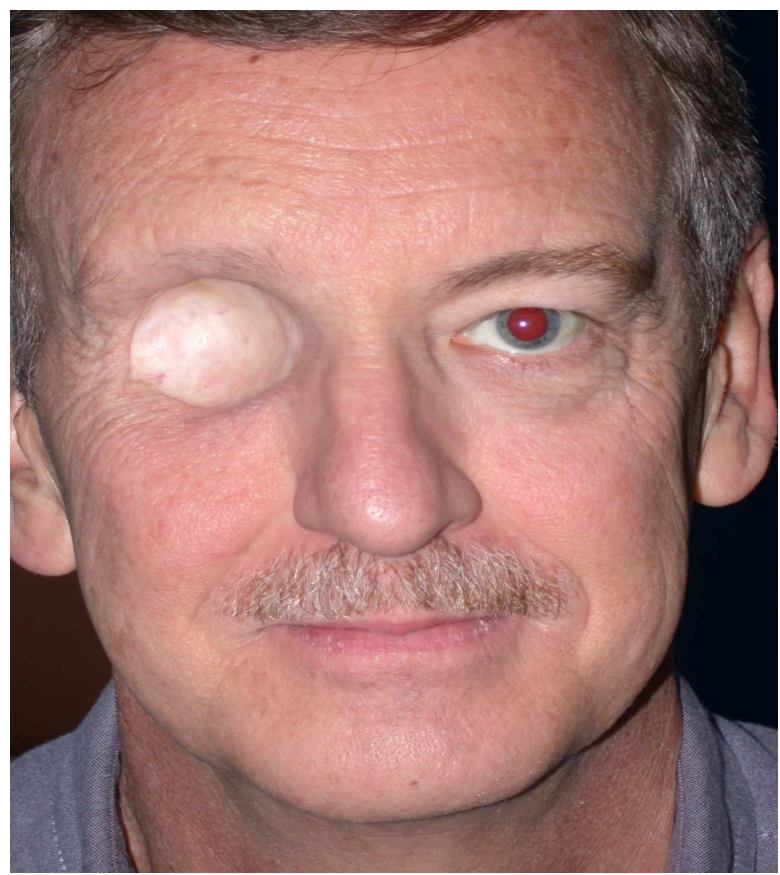

Photo 3. 


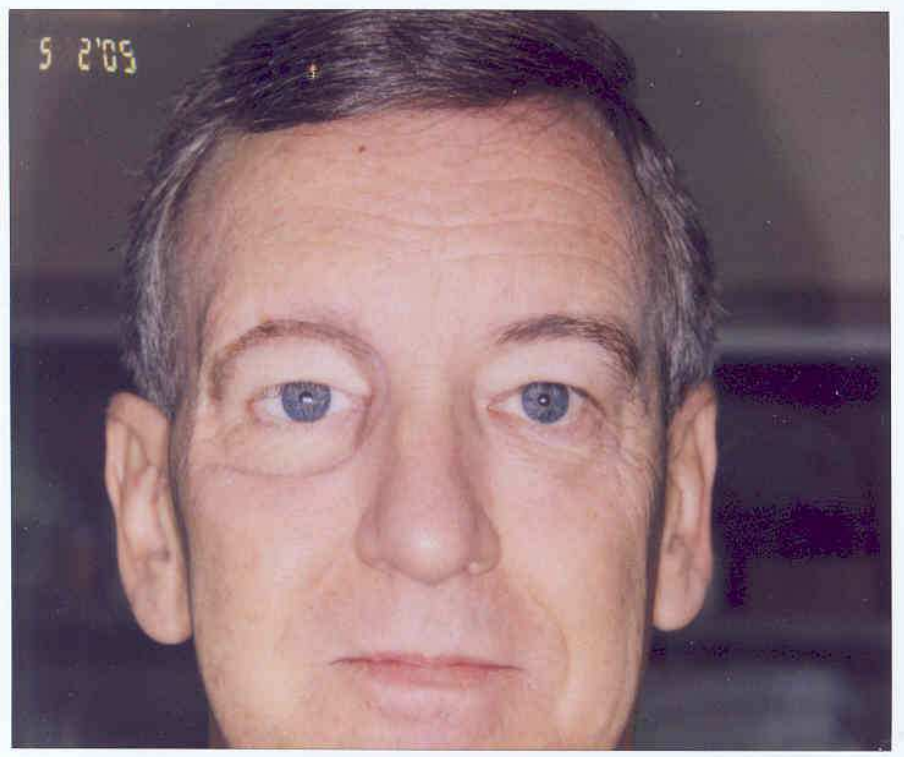

Photo 4 .

Three primary analytical categories were generated to illustrate patients' interaction with secondary groups leading to stigmatization: Intrusion, sympathy and benign neglect. Intrusion indicates interaction based on unsolicited attention paid to patients. Strangers and acquaintances ask unwanted questions, make unwelcome remarks, stare and/or make their unspoken curiosity felt. Sympathy refers to unsolicited comments and/or actions showing support to patients and the desire to be of assistance, while benign neglect denotes a situation in which interaction is characterized by people not paying particular attention to patients. Additionally, small and large groups also emerged as relevant categories as differences exist in interaction within these groups. Intrusion, sympathy and benign neglect describe conditions that are decreasingly favorable to the creation of stigma. As intrusion fosters stigma, benign neglect defines patterns on interaction in which patients are granted that kind indifference that is "normally" given to strangers and/or distant attention granted to acquaintances. 


\section{Brief review of salient literature on cancer generated facial disfigurement}

Stigma is defined as the "social disgrace" associated with people who are considered different (Goffman 1963). Difference is socially constructed and is the outcome of discrepancies between an individual virtual social identity (expectations about what that individual ought to be) and his/her actual social identity (the attributes he/she actually posses) (Goffman 1963:2). When the actual social identity is perceived as departing from normality, the individual is stigmatized. Stigma is attached to an individual's feature "that is deeply discrediting" and that separates that person from the group of the "normals." However, its actual genesis is relational as he/she is constantly compared to other members of society. Therefore, some specific individual characteristics generate stigma in some instances but not in others (de-stigmatization). Stigma is generated by the existence of a number of blemishes. There are those of individual character such as homosexuality, dishonesty, imprisonment, radical political behavior, and addiction. There are those of tribal stigma that are related to a person's group of reference such as religion, ethnicity or race. And there are those of "abominations of the body" that refer to physical abnormalities. Facial disfigurement pertains to this last category.

Stigma has been widely studied and this production includes works such as those on stigma generated from diseases (i.e., cancer and AIDS) (Fife and Wright, 2000), physical disabilities (Cahill and Eggleston, 1995; Susman 1994 Link and Phelan 2001:365-66; Jacobi 1994), and mental health (Angermeyer and Matschinger 1994; Corrigan and Penn 1999; Cahill and Eggleston, 1995). Despite this wealth of contributions, stigma caused by facial disfigurement has been the subject of only a relatively small number of works (Clarke 1999; Clarke et al. 2003; Kent, 2000; Kish and Lansdown 2000; Hughes, 1998; Pruizinsky et al. 2006). These analyses stress the social importance of the face, the problems that affect those who display visible facial blemishes and indicate that the face represents one of the most notable physical attributes and a significant source of social information prior to, and during, social interaction (Anderson and Franke 2002; Cole 1998; Furness et al. 2006; Goffman 1963; Hawkesworth 2001; Hughes, 1998; Macgregor 1974) Accordingly, people possessing an attractive face are not only considered physically pleasing, but they are often viewed as endowed with intellectual and emotional characteristics such as intelligence, kindness, and high morality and better treated by others than less attractive individuals (Bull and Rumsey 1998; Cash and Pruzinsky 2002; Feingold 1992; Kish and Lansdown 2000; Macgregor 1990). Facially disfigured individuals commonly engender negative responses by other members of society (Callahan, 2004; Hagedoorm and Molleman, 2006: Kish and Lansdown 2000). Stigma is further divided into felt stigma and enacted stigma (Jacobi 1994). Felt stigma refers to situations in which the individual perceive that he/she is viewed as different. Enacted stigma refers to explicit actions that result in stigma. In both instances, stigma is a relational process as it involves at least two interacting parties.

Facially disfigured cancer patients are primarily concerned with surviving cancer. Yet, as their survival becomes apparent, they become concerned with disfigurement: a situation that affects both patients and their family members (Bonanno 2009; van Doorne, van Waas and Bergsma 1994). The association of cancer and disfigurement is persistent. Therapy almost inevitably mandates surgical removal of cancer-affected parts of the face making it an undesirable consequence of successful medical intervention (Callahan 2004; Millsopp, Brandom, Humphris, and Lowe 2006; Valente 2004). 
Among the limits of this otherwise important literature, is the lack of attention paid to the social process that generates stigma (Kent 2000:199; Clarke 1999; Furness et al., 2006; Thompson and Kent 2001). In particular, limited attention has been paid to the fact that disfigurement and stigma are socially constructed and generated through processes of interaction that involve multiple actors and take different forms according to the settings in which they unfold (Kent 2000). Accordingly, it is important to recognize that attention paid to the adaptation of patients to their condition of facially disfigured is only one component of an otherwise much more complex process in which "others" are often the source of stigma. In this respect, and while evidence indicates that society as a whole is the primary source of stigma (Callahan, 2004; Hagedoorm and Molleman, 2006; Kish and Lansdown 2000; Pruzinsky et al. 2006; van Doorne et al. 1994:325), the manners through which stigma emerges in interaction between the patients and "others" requires further investigation (Bonanno, Choi and Esmaeli 2008). More specifically, because stigma does not occur homogeneously, it is important to identify the circumstances in which it appears in interaction and the ways in which interaction can be directed to avoid the occurrence of stigma. Van Doorne et al. (1994), for instance, indicate that interaction with strangers almost certainly leads to the creation of stigma. They, however, stress that interaction with acquaintances requires additional investigation. The present study addresses this gap in current knowledge.

\section{Results}

A model of interaction patterns between facially disfigured cancer patients and members of secondary groups was generated through the application of Grounded theory (Charmaz 2006; Holton 2007). Figure 1 graphically synthesizes this model.

In the case of the interaction of patients with members of secondary groups, three fundamental analytical categories were developed. Intrusion indicates interaction based on unsolicited attention paid to patients by strangers and acquaintances. People ask unwanted questions, make unwelcome remarks, stare and make their unspoken curiosity felt. Sympathy refers to unsolicited comments and/or actions showing support to patients and the desire to be of assistance. Finally, benign neglect denotes a situation in which interaction is characterized by people not paying particular attention to patients and giving them that "civil inattention" and/or distant attention that characterizes everyday interaction among strangers. Benign neglect is the desired form of interaction as it does not generate stigma.

Interaction patterns change in regard to the size of interacting groups. Interaction characterized by intrusion in large and small groups generates stigma. These are felt and enacted forms of stigma. Sympathy produces enacted stigma in interaction in small groups and enacted and felt stigma in interaction within large groups. As by definition, benign neglect does not produce stigma in interaction within all groups. Following are more detailed illustrations of these patterns.

Intrusion - This is a situation that engenders stigma in interaction within small and large groups alike. Members of interacting groups grant disfigured individuals the particular status of "different" through the construction of actions based on unwanted attention. Strangers and acquaintances' questions, stares, remarks constitute elements that transform disfigurement into stigma. Of particular importance are situations in which patients remain for relatively long periods of time in a relatively still position in full view of others. Because of this 
immobility, patients tend to feel uncomfortable. This felt stigma, however, can translate into enacted stigma as stares, comments, or questions characterized the behavior of others. The unusual shape of patient's face makes strangers and acquaintances curious. As this curiosity is made explicit, stigma occurs. This is the case even when interacting individuals attempt to conceal their intrusive behavior. This concealed enacted stigma refers to actions of intrusions accompanied by attempts to hide them from patients. Patients tend to feel resentment to intrusive actions. They resent the unwanted attention of others and often express this resentment by defining these actions as "rude" and "inconsiderate." Simultaneously, patients display unconcerned awareness. This is a pattern in which patients remain aware of stigmatizing actions but simultaneously indicate that are not affected by them.

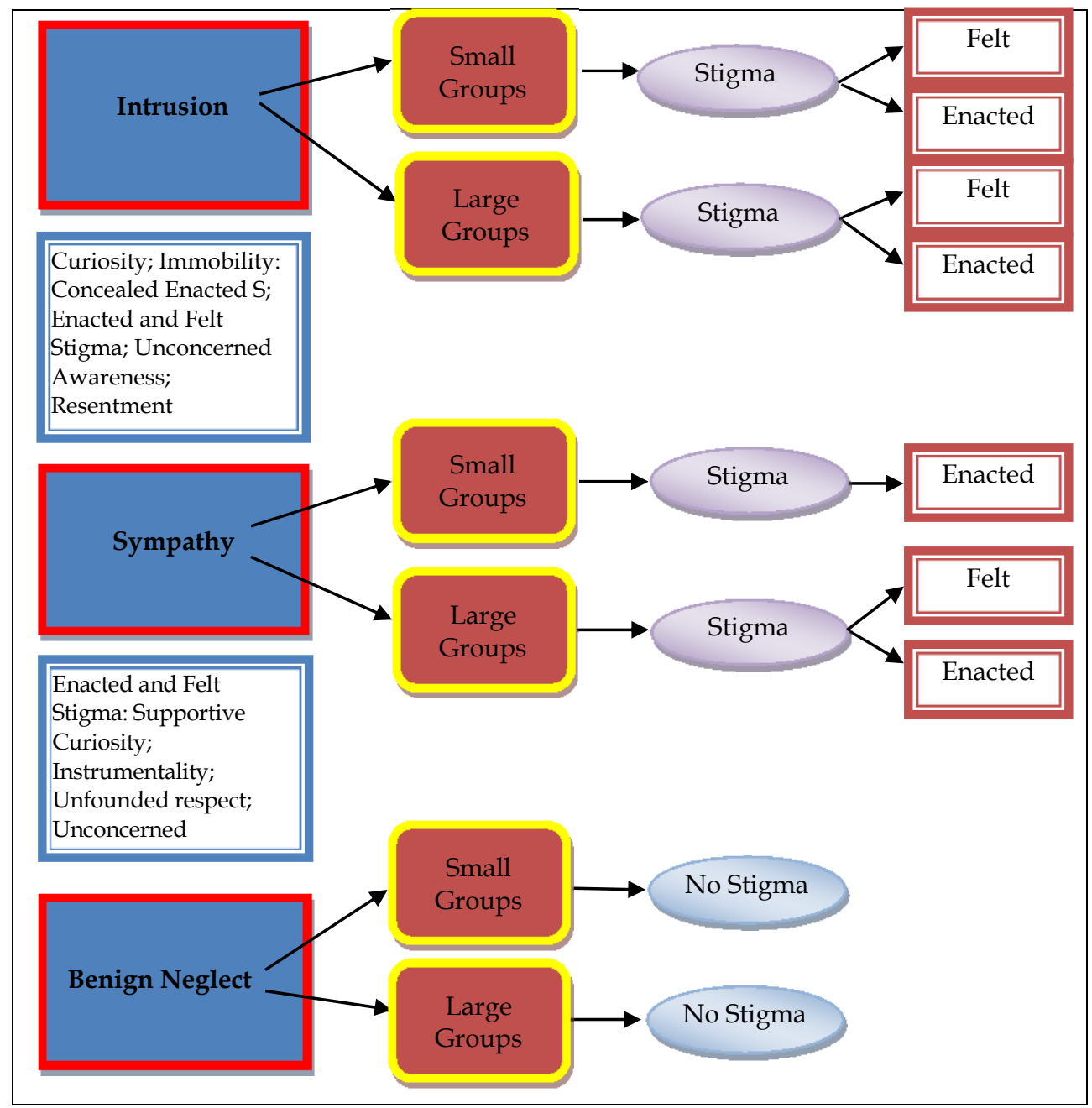

Fig. 1. 
Sympathy - It refers to intrusive patterns of interaction in which individuals provide and/or manifest support to facially disfigured patients. It creates enacted stigma in small group interaction and felt and enacted stigma in large group interaction. In the case of small group interaction, supportive curiosity occurs. It refers to questions that people ask about patients' appearance that are accompanied by actions and expressions that are supportive of patients. It is a form of enacted stigma. The expression "everybody is nice," frequently reported by patients, captures this pattern of interaction. Patients do not experience felt stigma as they feel comfortable with the support that strangers and acquaintances offer. In large group interaction, patients may use this offered support to their advantage even when it is not necessary. This instrumentality is not exercised in small groups. Interaction in large groups, however, leads to stigma when offered assistance is viewed as unnecessary and/or exaggerated in relation to the actual physical conditions of patients. Simultaneously, when sympathy guided action transcends established expectations and creates unfounded attention enacted stigma occurs in small and large groups. Because of their status of cancer survivors and facially disfigured individuals, patients are granted what they perceive as undeserved respect. These actions create felt stigma.

Benign Neglect - refers to interaction in which strangers and acquaintances do not pay particular attention to disfigured individuals. It is that common pattern that characterizes interaction among people who are not familiar with each other. While people are aware of the presence of others, they do not focus on, nor pay particular attention to, their actions. As Macgregor (1974: 60) put it, "it is that civil inattention normally granted to others in society." Because of its "normality," interaction characterized by benign neglect becomes particularly important in situations in which difference is present. Facially disfigured individuals not only feel comfortable during these interactions, but also acknowledge the fact that they are treated normally without any particular emphasis placed on their physical appearance.

\section{Relevance of these findings for surgeons and other caregivers}

This study demonstrates the ways in which interaction between facially disfigure cancer patients and secondary groups creates stigma. Because only limited knowledge is available on this topic, caregivers should use these results to assist patients and provide needed information and assistance to patients' family members. Through a grounded theory analysis, the study identifies key types of interaction patterns related to social stigma. These findings add to existing knowledge in a variety of ways. First, they point out that interaction between facially disfigure cancer patients and secondary groups is not a uniform process but it varies according to different settings and groups. It follows that current knowledge that indicates that "the reaction of people on the streets or in the neighborhood is .... consistent: they stare at most patient with facial defect" (van Doorne at al 1994:325; see also Hughes 1998; Macgregor 1990), while overall accurate, requires to be specified. This research demonstrates that the behavior of members of secondary groups consists of three distinct interaction patterns.

Benign neglect is the only type of interaction that does not create stigma. It refers to "normal" interaction as individuals are aware of the presence of others but do not pay particular attention to them. Accordingly, patients and their family members should be informed on the importance of creating conditions that lead to this type of interaction. In 
particular, patients and family members should be instructed on the tendency of people to pay unwanted attention to patients. This is a situation that should be addressed through action planning and education whereby patients ought to plan their social activities carefully. Similarly, the general public should receive education on the conditions of these patients ${ }^{1}$.

Interaction characterized by intrusion consistently generates felt and enacted stigma. Episodes of felt and enacted stigma occur in small and large group settings, making it the most difficult type of interaction for patients and family members. Patients and their families should be advised of the difficulties that episodes of intrusion generate. Strangers and acquaintances alike will ask questions, make comments, stare and make other intrusive actions. A number of additional elements characterize this type of interaction. The categories of curiosity; immobility; unconcerned awareness and resentment discussed above frequently accompany intrusion. As indicated above, educational efforts should be made to sensitize the general public on episodes of intrusion. It is also important to inform patients and their family members that these conditions may or may not be alleviated by reconstructive surgery.

In the case of interaction characterized by sympathy, stigma develops in different ways in small groups than in large groups. In small groups stigma takes the form of enacted stigma. In large groups it takes the forms of both enacted and felt stigma. While sympathy indicates that interacting individuals either provide or manifest support to facially disfigured patients, it also refers to the fact that this interaction ultimately creates stigma. The categories of supportive curiosity, instrumentality and unfounded respect characterize this type of interaction. Caregivers should make clear to patients and family members that the desire of strangers and acquaintances to assist patients does not necessarily translate into a non-stigmatized interaction. Accordingly, efforts to educate interested parties on this contradictory situation can be beneficial.

Second, this study indicates that acquaintances' interaction with patients does not differ significantly from that recorded for strangers. Both strangers and acquaintances contribute to the creation of stigma when intrusion and sympathy occur. Both groups are capable, however, to establish interaction based on benign neglect. These findings add to existing knowledge by clarifying patterns of interaction between patients and acquaintances.

Third, this research underscores the importance of approaching the creation of stigma for facially disfigured cancer patients in relational terms. Stigma emerges as the product of interaction. As such, it involves facially disfigured patients and other segments of society as they interact in varying ways and with varying results. While the study of the manner through which individuals respond to disfigurement remains important, an enhanced understanding of the construction of stigma is achieved by considering the collective dimension of this process. Caregivers should be aware of this aspect and avoid the

\footnotetext{
${ }^{1}$ The patterns of actions needed to address stigma are not the topic of this chapter. However, it is important to note that both education of the public and action planning are to be considered two of the most important strategies to address this problem.
} 
presentation of stigma as an issue that pertains exclusively to the patients' individual sphere. Stigma is a collective process that involves a multiplicity of actors.

Finally, the issue of stigma associated to cancer generated facial disfigurement is the byproduct of advancements in medicine and surgical techniques. It is a situation that is the outcome of the success of scientific advancements. However, it is a state of affairs that cannot be address exclusively by medicine in general and surgical actions in particular. It requires a multidisciplinary effort and the cooperation of multiple actors in the medical sciences as well as the social and behavioral sciences. Accordingly, it is important that surgeons become aware of this and similar conditions and that these situations become integrated into training protocols. Surgeons as well as other caregivers should be exposed to knowledge about the creation of pertinent social problems and to the boundaries that surgical intervention entails for the overall quality of life of patients.

\section{References}

Angermeyer M. \& Matschinger H. (1994). Lay beliefs about schizophrenic disorder: the results of a population study in Germany.Acta Psychiatrica Scandinavica. 89, 39-45.

American Cancer Society. (2009). Detailed guide: Eye cancer. Retrieved July 5, 2009 from www.cancer.org.

Anderson, R.C. \& Franke, K.A. (2002). Psychological and psychosocial implications of head and neck cancer. Internet Journal of Mental Health, 1 (2), 55-64.

Berremberg, J.L. (1989). Attitudes towards cancer as a function of experience with the disease: A test of three models. Psychology and Health, 3,233-243.

Bloom, J. \& Kessler, L. (1994). Emotional support following cancer: A test of the stigma and social activity hypothesis. Journal of Health and Social Behavior, 35,118-133.

Bonanno, A. \& Choi J.Y. (2009). Psychosocial aspects of orbitofacial disfigurement in cancer patients. In B. Esmaeli, (ed.) Ophthalmic Oncology (pp. 311-319). Norwell, MA: Springer.

Bonanno, A., Choi, J.Y., \& Esmaeli, B. (2008, March). The contradictions of medical sociology understanding of stigma in facially disfigured individuals. Paper presented at the Annual Meeting of the Southwest Social Science Association. Las Vegas, NV.

Bull, R. \& Rumsey, N. (1988). The social psychology of facial appearance. New York: Springer Vale.

Bull, R. \& Stevens. J. (1981). The effects of facial disfigurement on helping behavior. The Italian Journal of Psychology, 8 (1) April.

Cahill, S., and Eggleston, R. (1995). Reconsidering the stigma of physical disability: wheelchair use and public kindness. The Sociological Quarterly, 36(4), 681-698.

Callahan, C. (2004). Facial disfigurement and sense of self in head and neck cancer. Social Work in Health Care, 40(2),73-87.

Cash T.F., \& Pruzinsky, T. (eds.) (2002). Body image. A handbook of theory, research, and clinical practice. New York: The Guilford Press.

Charmaz, K. (2006). Constructing grounded theory. A practical guide though qualitative analysis. London: Sage. 
Clarke, A. (1999). Psychosocial aspects of facial disfigurement: problems, management and the role of a lay-led organization. Psychology, Health and Medicine, 4(2),127-142.

Clarke, A., Rumsey, N., Collin, JRO \& Wyn-Williams M.. (2003). Psychological distress associated with disfiguring eye conditions. Eye, 17,35-40.

Cole, J. (1998). About face. Cambridge: The MIT Press.

Corrigan, P.W. \& Penn, D. L. (1999). Lessons from social psychology on discrediting psychiatric stigma. American Psychologist, 54,765-76.

Davis, K., Wingo, P., \& Parker S. (1998). Cancer statistics by race and ethnicity. CA Cancer J Clin 1,31-47.

Davis, K., Roumanas E.D., \& Nishimura R.D. (1997). Prosthetic-surgical collaboration in the rehabilitation of patients with head and neck defects. Otolaryngologic Clinics of North America, 30 (4), 631-645.

Dropkin, M.J. (1999). Body image and quality of life after head and neck cancer surgery. Cancer, Practice November/December 7(6), 309-313.

Esmaeli, B. (2009) (ed.). Ophthalmic Oncology. Norwell, MA: Springer.

Fife, B. L., \& Wright, E. R. (2000). The dimensionality of stigma: A comparison of its impact on the self of persons with HIV/AIDS and cancer. Journal of Health Social Behavior, $42,50-67$.

Feingold, A. (1992). Good looking people are not what we think. Psychological Bulletin, 111, 304-341.

Furness, P., Garrud, P., Faulder, A., \& Swift, J. (2006). Coming to terms. A grounded theory of adaptation to facial surgery in adulthood. Journal of Health Psychology, 11 (3), 453466.

Goffman, E. (1963). Stigma. Notes on the management of spoiled identity. New York: Simon \& Shuster.

Hagedoorm, M. \& Molleman, E., (2006). Facial disfigurement in patients with head and neck cancer: The role of social self-efficiency. Health Psychology, 25(5), 643-647

Hawkesworth, M. (2001). "Disabling spatialities and the regulation of a visible secret." Urban Studies, 38(2),299-318.

Hughes, M. (1998). The social consequences of facial disfigurement. Aldershot: Ashgate.

Holton. J.A. (2007). The Coding Process and its Challenges. in A, Bryant and K. Charmaz, The SAGE handbook of grounded theory (pp. 265-289). Los Angeles: SAGE Publications.

Ishii, L., Carey, J. Byrne, P. Zee, D.S., and Ishii, M. (2009). “Measuring attention bias to peripheral facial deformities" The American Laryngological, 119, 459-465.

Jackson, L. A. (2002). Physical attractiveness: A sociostructural perspective. In Cash, T.F. and Pruzinsky, T. (Eds.) Body image. A handbook of theory, research, and clinical practice (pp. 13-21). New York: The Guilford Press.

Jacobi, A. (1994). Felt versus enacted stigma: A concept revisited. Social Science and Medicine, $38(2), 269-274$.

Kent, G. (2000). Understanding the experiences of people with disfigurements: An integration of four models of social and psychological functioning. Psychology, Health $\mathcal{E}$ Medicine, 5(2),117-129. 
Kish, V. \& Lansdown, R. (2000). Meeting the psychosocial impact of facial disfigurement: developing a clinical service for children and families. Clinical Child Psychology and Psychiatry, 5(4), 497-512.

Link, B.G. and Phelan, J.C.. (2001). Conceptualizing stigma. Annual Review of Sociology, 27,363-85.

Macgregor, F. (1990). Facial disfigurement: problems and management of social interaction and implication for mental health. Aesthetic and Plastic Surgery, 14 (4), 249-257. (1974). Transformation and Identity: The Face and Plastic Surgery. New Your: Quadrangle/The New York Times Book Co.

Millsopp, L. Brandom, L., Humphris G., \& Lowe D., (2006). Facial appearance after operations for oral and oropharyngeal cancer: A comparison of casenotes and patient-completed questionnaire. British Journal of Oral and Maxillofacial Surgery, 44, 358-363.

Millstone, S. (2008). Facial Discrimination. Therapy Today, 19, 35-38.

Mood, D. W. (1997). Cancers of the head and neck. In C. Varricchio (ed.) A Cancer Source Book for Nurses (pp. 271-283). Sudbury, MA: Jones and Bartlett Publishers.

Mosher, C. \$ Danoff-Burg, S. (2007). Death anxiety and cancer related stigma: A terror management analysis Death Studies, 31,855-907.

Newell, R. J. (1999). Altered body image: A fear-avoidance model of psycho-social difficulties following disfigurement. Journal of Advanced Nursing, 30 (5),1230-38.

Partridge, J. (1998). Changing faces: taking up Macgregor' s challenge. Journal of Burn Care and Rehabilitation, 19,174-180.

Pruzinsky, T.; Levine, E., Persing J.A., Barth, J.T., \& Obrecht, R.. (2006). “Facial trauma and facial cancer." in Sarwer, D.B., Pruzinsky, T. F., T., Goldwyn, R.M., \& Persing, J.A. Psychological Aspects of Reconstructive and Cosmetic Plastic Surgery: Clinical, Empirical and Ethical Perspectives (pp.125-143). Philadelphia PA: Lippincott Williams.

Rybarczyk B.D, \& Behel, J.M. (2002). Rehabilitation medicine and body image. In Cash T.F. \& Pruzinsky, T. (eds.) Body image. A handbook of theory, research, and clinical practice (pp. 387-393). New York: The Guilford Press.

Susman, J. (1994). Disability, stigma and deviance. Social Science and Medicine, 38, 15-22.

Synnott, A. (1989). Truth and Goodness, Mirrors and Masks - Part I: A sociology of beauty and the face. The British Journal of Sociology, 40 (4): 607-636.

Thompson, A. \& Kent, G., (2001). Adjusting to disfigurement: process involved in dealing with being visibly different. Clinical Psychology Review, 21(5):663-682.

Valente, S. (2004). "Visual disfigurement and depression." Plastic Surgical Nursing, 24 (4) 14146.

van Doorne J.M., van Waas, M.A., \& Bergsma, J. (1994). Facial disfigurement after cancer resection: a problem with an extra dimension. Journal of Investigative Surgery, 7 (4):321-326.

Vickery, LE; Latchford, G., Hewinson, J., Bellew, M., \& Faber, T. (2003). The impact of head and neck cancer and facial disfigurement on the quality of life of patients and their partners. Head E Neck 25 (4):289-96. 
Weiner, B., Perry, R.P., \& Magnusson, J. (1988). “An attributional analysis of reaction to stigma." Journal of Social Issues, 35 (1):120-55. 


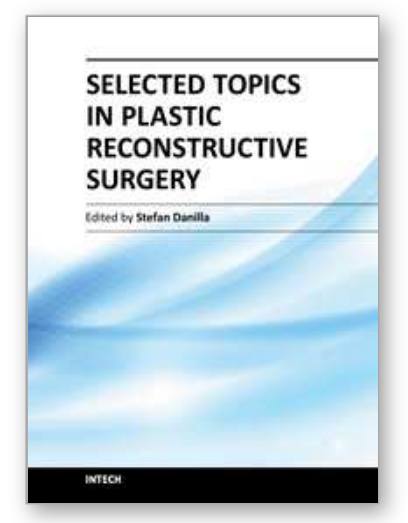

\author{
Selected Topics in Plastic Reconstructive Surgery \\ Edited by Dr Stefan Danilla
}

ISBN 978-953-307-836-6

Hard cover, 242 pages

Publisher InTech

Published online 20, January, 2012

Published in print edition January, 2012

Plastic Surgery is a fast evolving surgical specialty. Although best known for cosmetic procedures, plastic surgery also involves reconstructive and aesthetic procedures, which very often overlap, aiming to restore functionality and normal appearance of organs damaged due to trauma, neoplasm, ageing tissue or iatrogenesis. First reconstructive procedures were described more than 3000 years ago by Indian surgeons that reconstructed nasal deformities caused by nose amputation as a form of punishment. Nowadays, many ancient procedures are still used like the Indian forehead flap for nasal reconstruction, but as with all fields of medicine, the advances in technology and research have dramatically affected reconstructive surgery.

\title{
How to reference
}

In order to correctly reference this scholarly work, feel free to copy and paste the following:

Alessandro Bonanno (2012). The Social Limits of Reconstructive Surgery: Stigma in Facially Disfigured Cancer Patients, Selected Topics in Plastic Reconstructive Surgery, Dr Stefan Danilla (Ed.), ISBN: 978-953-307-836-6, InTech, Available from: http://www.intechopen.com/books/selected-topics-in-plastic-reconstructive-surgery/thesocial-limits-of-reconstructive-surgery-stigma-in-facially-disfigured-cancer-patients

\section{INTECH}

open science | open minds

\section{InTech Europe}

University Campus STeP Ri Slavka Krautzeka 83/A 51000 Rijeka, Croatia Phone: +385 (51) 770447

Fax: +385 (51) 686166 www.intechopen.com

\section{InTech China}

Unit 405, Office Block, Hotel Equatorial Shanghai No.65, Yan An Road (West), Shanghai, 200040, China 中国上海市延安西路65号上海国际贵都大饭店办公楼405单元 Phone: +86-21-62489820

Fax: $+86-21-62489821$ 
(C) 2012 The Author(s). Licensee IntechOpen. This is an open access article distributed under the terms of the Creative Commons Attribution 3.0 License, which permits unrestricted use, distribution, and reproduction in any medium, provided the original work is properly cited. 